\title{
The equity premium and the allocation of income risk*
}

\author{
Jean-Pierre Danthine \\ Université de Lausanne, CH-1015 Lausanne, Switzerland \\ CEPR, London, England
}

John B. Donaldson

Columbia University, New York, NY 10027, USA

\author{
Rajnish Mehra \\ University of California, Santa Barbara, CA 93106, USA
}

\begin{abstract}
This paper examines the extent to which the equity premium puzzle can be resolved by taking account of the fact that stockholders bear a disproportionate share of output uncertainty. We do this in the context of a non-Walrasian $\mathrm{RBC}$ model where risk reallocation is justified by borrowing restrictions. The risk shifting mechanism we propose has the same effect as would arise from an increase in the risk aversion parameter of the representative agent and thus contributes to a rise in the equity premium. As with more standard RBC models, it remains that our model is unable to replicate key financial statistics. In particular, the observation that the equity return is more variable than national product cannot be accounted for under standard technology assumptions.
\end{abstract}

\section{Introduction}

From a theoretical viewpoint, among the most general asset pricing models developed to date are those of Lucas (1978) (discrete-time exchange model), Brock $(1979,1982)$ and Prescott and Mehra (1980) (discrete-time production

\footnotetext{
${ }^{*}$ Computing resources were generously provided by the Center for the Study of Futures Markets, Columbia University. Financial support from the Faculty Research Fund, Graduate School of Business, Columbia University and the Fonds National de la Recherche Scientifique is gratefully acknowledged.

This study was completed while Danthine and Donaldson visited the Institute for Empirical Macroeconomics at the Federal Reserve Bank of Minneapolis. The comments and questions of individual Bank staff members and Bank seminar participants have very significantly contributed to its improvement. We wish especially to thank Edward C. Prescott for several stimulating discussions and Gary Hansen for providing important background information.
} 
formulations), and Breeden (1979), Cox, Ingersoll, and Ross (1985), and Merton (1973) (continuous time). This class of models is referred to generically as the consumption capital asset pricing model (CCAPM). All are essentially decentralized versions of the one-good representative agent stochastic growth model.

Unfortunately, empirical tests of these models have led without exception to their rejection. Perhaps the most striking of these rejections is contained in the study of Mehra and Prescott (1985). In a representative agent setting, a variant of Lucas (1978), they show that for reasonable values of the discount factor and the coefficient of relative risk aversion the implied equity premium is too low when the model is calibrated to reflect historically observed aggregate consumption growth rates. ${ }^{1}$ It is customary to refer to this enigma as the equity premium 'puzzle'.

Parallel to these developments in financial theory and built upon the same theoretical foundations (the one-good stochastic growth model) is the stream of macroeconomic research known as Real Business Cycle (RBC) Theory. While researchers have found that this same class of models more easily replicates the essential macroeconomic features of the business cycle [see, e.g., Kydland and Prescott (1982) and Hansen (1985)], a number of inconsistencies have nevertheless emerged. For example, it has been a challenge to explain the observed relative variability of employment and productivity - the so-named 'employment-variability paradox' [Prescott (1986)].

This common theoretical basis for financial and macroeconomic models provides a rich source of research opportunities. On the one hand, it opens the way for the simultaneous 'cross-model verification' of both financial and macroeconomic models. In particular, it imposes an additional discipline on proposed solutions to the aforementioned two puzzles: a solution to the equity premium puzzle, in order to be fully legitimate, must not diminish the ability of the model to replicate the macroeconomic stylized facts and, reciprocally, improvements in business cycle modelling cannot come at the expense of the model's ability to replicate financial regularities. After all, it is the actions of the same agents that give rise to these economic phenomena.

In addition, the methodological convergence outlined above provides the opportunity for a more careful understanding of the influence of the macroeconomy on the behavior of asset prices. Very much in this spirit, Mehra and Prescott (1985), in their original study, propose that the magnitude of the equity premium may be in part the result of income risk shifting from workers to equity owners in the context of labor contracts. They write (p. 157): 'Labor contracts may incorporate an insurance feature, as labor claims on output are in part fixed, having been negotiated prior to the

\footnotetext{
'In Lucas' (1978) model, consumption levels follow a stationary process. Mehra and Prescott (1985) allow for growth and nonstationary consumption, with the rate of growth of consumption following a stationary process. For a detailed exposition see Mehra (1988).
} 
realization of output. Hence, a disproportionate part of the uncertainty in output is probably born by equity owners.' It is this hypothesis which we intend to explore more thoroughly, in the context of a non-Walrasian RBC model first introduced in Danthine and Donaldson $(1991 \mathrm{a}, \mathrm{c}){ }^{2}$ Essentially, the model is one in which the effects of capital market imperfections are ameliorated through labor market contracting and a social risk-sharing arrangement. These latter aspects together guarantee partial risk shifting from workers to stockholders. Such a setting further allows us to evaluate the model in the light of recent work by Mankiw and Zeldes (1991) who find that stockholder consumption is both more volatile and more highly correlated with returns to stock ownership than is the consumption of nonstockholders (workers in our model).

This effort is undertaken in the context of a more general survey of the asset pricing implications of several $\mathrm{RBC}$ models, with emphasis on the equity premium puzzle. We start from the neoclassical growth model itself; that is, from a decentralized pure Walrasian formulation where the employment-productivity variability puzzle is present in striking relief. We next compute the equity premium implied by Hansen's (1985) indivisible labor model, which elegantly resolves the employment variability puzzle. Maintaining the same perspective, we conclude with an evaluation of the nonWalrasian model introduced above.

An outline of the paper is as follows: Section 2 reviews the financial and macroeconomic stylized facts, while section 3 details the three models of concern. Section 4 provides a comparative numerical analysis of the properties of these models while providing insights into the sources of their relative performance characteristics. Section 5 concludes the paper.

\section{The macroeconomic and financial stylized facts}

The statistics summarized in table 1 for the U.S. economy characterizes the minimal set of macroeconomic regularities that theoretical models should be able to replicate. Qualitatively, we observe that investment is more variable than output, while consumption is less variable and capital stock much less so. The variation in hours is approximately the same as that of the output, and substantially exceeds the variation in average productivity. All variables are highly procyclical except the stock of capital whose contemporaneous correlation with output is nearly zero. While these regularities are generally

\footnotetext{
${ }^{2}$ Many other attempts to resolve the equity premium 'puzzle' have been proposed. Without attempting to be exhaustive, a partial listing of suggested resolutions is as follows: nondiversifiable risk [Mankiw (1986)], small probability events of ruin [Reitz (1988)], heterogeneous beliefs [Abel (1990)], habit formation [Constantinides (1988)], and a time-varying lower bound on consumption [Nason (1988)]. For various reasons, however, few of these theories have met with general acceptance.
} 
Table 1

Summary statistics: U.S. economy.

Standard deviation in percent (a), standard deviation rclative to the standard deviation of output (b), contemporaneous correlation with output (c). ${ }^{a}$

\begin{tabular}{lccc}
\hline Series & (a) & (b) & (c) \\
\hline Output & 1.76 & 1.00 & 1.00 \\
Consumption & 1.29 & 0.73 & 0.85 \\
Investment & 8.60 & 4.89 & 0.92 \\
Capital stock & 0.63 & 0.36 & 0.04 \\
Hours (employment) & 1.66 & 0.94 & 0.76 \\
Productivity (average) & 1.18 & 0.67 & 0.42 \\
\hline
\end{tabular}

\footnotetext{
${ }^{\mathrm{a}}$ Source: Hansen (1985, table 1 ); these results are derived from quarterly data that have been detrended using the Hodrick and Prescott (1980) filter.
}

Table 2

Annual returns, $1889-1978 .^{a}$

\begin{tabular}{llr}
\hline Series & Mean & Standard deviation \\
\hline Market return $\left(r_{\mathrm{e}}\right)$ & \multicolumn{2}{c}{ (in percentage terms) } \\
Risk-free rate $\left(r_{\mathrm{b}}\right)$ & 7.00 & 16.5 \\
Equity premium $\left(r_{\mathrm{e}}-r_{\mathrm{b}}\right)$ & 0.8 & 5.7 \\
& 6.2 & 16.7
\end{tabular}

${ }^{a}$ Source: Mehra and Prescott (1985).

observed in other developed countrics, there are notablc exceptions [see Danthine and Donaldson (1991b) who qualify the statement that table 1 defines the business cycle internationally].

On the financial side the key observations are summarized in table 2. More detailed information, in particular values of the different statistics obtained for different subperiods, can be found in Mehra and Prescott (1985). We note principally that the average equity premium in the 1889-1978 period has been of the order of 6 percent, arising from an average market return of 7 percent and an average risk-free rate somewhat below 1 percent.

Two other statistics are relevant for our future analysis. First, over the period in question, the average growth rate of consumption was 1.8 percent, with a standard deviation of 3.6 percent. Second, Mankiw and Zeldes (1991) report that the correlation between the risk premium and the consumption growth rate was 0.4 for the same data set.

We now turn to an overview of the models in question.

\section{Asset pricing in RBC models}

In this section, we briefly review the characteristics of three distinct RBC models, while showing that the essential pricing equation takes the same 
form [first suggested by Lucas (1978)] in all three. It is the treatment of the labor market that principally differentiates these models.

\subsection{The canonical optimal growth model}

The foundation for all dynamic equilibrium macroeconomic models is the neoclassical optimal growth paradigm, augmented to allow for a labor-leisure choice. As demonstrated in Prescott and Mehra (1980), the optimal dynamic path of macro aggregates (consumption, investment, etc.) in this model corresponds to the growth path of a decentralized Walrasian economy in recursive competitive equilibrium. It is fully described as the solution to the following central planning problem:

$$
\max _{\left\{\left(c_{t}\right),\left(n_{t}\right)\right\}} \mathrm{E}\left(\sum_{t=0}^{\infty} \beta^{t} u\left(c_{t}, l_{t}\right)\right),
$$

subject to

$$
\begin{aligned}
& c_{t}+i_{t} \leq f\left(k_{t}, n_{t}\right) z_{t}, \\
& k_{t+1}=(1-\delta) k_{t}+i_{t}, \\
& l_{t}+n_{t}=1, \\
& k_{0}>0 \text { given. }
\end{aligned}
$$

In the above model, $c, i, k, l$, and $n$ denote, respectively, per capita consumption, investment, capital stock, leisure, and labor services (hours) provided in period $t ; f()$ is the period production technology which is subject to a stochastic disturbance $z, u()$ the period utility function, $\mathrm{E}$ the expectations operator, $\beta$ the subjective discount factor, and $\delta$ the period depreciation rate. The stochastic disturbance is assumed to follow a Markov process with transition function $Q\left(z, \mathrm{~d} z^{\prime}\right)$.

The analysis of this problem is well known. Under quite general regularity conditions, the necessary first-order conditions for problem (1) are given by

$$
\begin{aligned}
n: \quad u_{1}(c, 1-n) f_{2}(k, n) z=u_{2}(c, 1-n), & \\
i: \quad u_{1}(c, 1-n)= & \beta \int u_{1}\left(c^{\prime}, 1-n^{\prime}\right) \\
& \times\left[f_{1}\left(k^{\prime}, n^{\prime}\right) z^{\prime}+(1-\delta)\right] Q\left(z, \mathrm{~d} z^{\prime}\right),
\end{aligned}
$$

where $c=f(k, n) z-i$ and the subscript $i=1,2$ denotes the first partial 
derivative with respect to the $i$ th argument. A primed variable denotes next period's value of that variable. Eqs. (2) and (3) have as their (unique) solution a pair of stationary policy functions, $i(k, z)$ and $n(k, z)$, which completely determine the time path of the economy. Recalling that these functions may also be viewed as measuring the aggregate investment and labor supply of a decentralized economy in recursive equilibrium, we can (conditionally) price a risk-free bond (which guarantees the delivery next period of one unit of consumption in every state of nature) in zero net supply by the equation

$$
u_{1}(c, 1-n) p_{\mathrm{b}}(k, z)=\beta \int u_{1}\left(c^{\prime}, 1-n^{\prime}\right) \cdot 1 \cdot Q\left(z, \mathrm{~d} z^{\prime}\right)
$$

The (conditional) period risk-free rate $r_{\mathrm{b}}(k, z)$ is then determined by

$$
\left(1+r_{\mathrm{b}}(k, z)\right)=\frac{1}{p_{\mathrm{b}}(k, z)}
$$

In this environment, the equity security represents title to an infinite stream of dividends, $d(k, z)$, defined by

$$
d(k, z)=f(k, n) z-n f_{2}(k, n) z-i=c(k, z)-w(k, z)
$$

where $w($ ) denotes the period aggregate wage bill.

Accordingly, the (conditional) price of the equity security (the market portfolio) is defined recursively by the equation

$$
p_{\mathrm{e}}(k, z)=\beta \int \frac{u_{1}\left(c^{\prime}, 1-n^{\prime}\right)}{u_{1}(c, n)}\left[d\left(k, z^{\prime}\right)+p_{\mathrm{e}}\left(k^{\prime}, z^{\prime}\right)\right] Q\left(z, \mathrm{~d} z^{\prime}\right) .
$$

It follows that the conditional expected return on the market portfolio, $r_{\mathrm{e}}(k, z)$, is defined by

$$
r_{\mathrm{e}}(k, z)=\int\left[\frac{p_{\mathrm{e}}\left(k^{\prime}, z^{\prime}\right)+d\left(k^{\prime}, z^{\prime}\right)}{p_{\mathrm{e}}(k, z)}-1\right] Q\left(z, \mathrm{~d} z^{\prime}\right),
$$

given $k^{\prime}=(1-\delta) k+i(k, z)$.

For this model - and those to follow - we have adopted an asset pricing perspective similar to that of Lucas (1978). That is, the specification of the economy and the notion of equilibrium are used to generate a sequence of dividends for the shareholder. We then price this (time-stationary) dividend stream as though it were an 'exogenous' dividend process as per some Lucas (1978) 'tree model'. 
We next consider a modified (Walrasian) model with nonconvexities in the representative agent's choice set.

\subsection{Hansen's indivisible labor economy}

In the most elegant Walrasian solution to the employment variability puzzle offered to date, Hansen (1985) models an economy with a restricted labor-leisure choice. In particular, he proposes to take account of the fact that real world workers cannot continuously adjust their working time, but are generally limited to working full time or not at all. The nonconvexity such indivisibilities introduce in the agents' consumption sets is avoided by assuming that households choose among lotteries specifying the probability of working full time. Such lotteries implicitly define the contracts exchanged between firms and workers. Assuming a log-additive period utility function,

$$
u(c, l)=\log c+B \log l, \quad B>0
$$

Hansen (1985) shows that the period preferences defined over consumption and lotteries (indexed by the probability of working full time, say $n_{0}$ hours, $\left.n_{0}<1\right)$ are represented by

$$
u(c, l)=\log c+B \xi \log \left(1-n_{0}\right)
$$

where $\xi$ denotes the probability of working full time.

Given this transformation, the dynamic time path of the decentralized economy can be expressed as the solution to the problem

$$
\max _{\left\{\left(c_{t}\right),\left(\xi_{t}\right)\right\}} \mathrm{E}\left(\sum_{t=0}^{\infty} \beta^{t} u\left(c_{t}, \xi_{t}\right)\right),
$$

subject to

$$
\begin{aligned}
& c_{t}+i_{t} \leq f\left(k_{t}, n_{t}\right) z_{t}, \\
& k_{t+1}=k_{t}(1-\delta)+i_{t}, \\
& n_{t}=\xi_{t} n_{0}, \\
& k_{0} \text { given, }
\end{aligned}
$$

where the notation is as in problem (1). The necessary first-order conditions for problem (9), again under very general conditions [see Hansen (1985)], are 
given by

$$
\begin{aligned}
& \xi: \quad u_{1}\left(c, 1-\xi n_{0}\right) f_{2}\left(k, \xi n_{0}\right)=u_{2}\left(c, 1-\xi n_{0}\right) \\
& i: \quad u_{1}\left(c, 1-\xi n_{0}\right)= \beta \int u_{1}\left(c^{\prime}, 1-\xi^{\prime} n_{0}\right) \\
& \times\left[f\left(k^{\prime}, \xi^{\prime} n_{0}\right) z^{\prime}+(1-\delta)\right] Q\left(z, \mathrm{~d} z^{\prime}\right) .
\end{aligned}
$$

This indivisibility feature substantially alters the time paths of the various state variables relative to the canonical model of section 3.1: for the same shock distribution, output, investment, and hours are more variable, the latter especially so as compared to the variation in productivity.

The general form of the relevant asset pricing equations is unchanged from the canonical model:

$$
\begin{aligned}
& u_{1}\left(c, 1-\xi n_{0}\right) p_{\mathrm{b}}(k, z)=\beta \int u_{1}\left(c^{\prime}, 1-\xi^{\prime} n_{0}\right) \cdot 1 \cdot Q\left(z, \mathrm{~d} z^{\prime}\right), \\
& p_{\mathrm{e}}\left(k, z_{t}\right)=\beta \int \frac{u_{1}\left(c^{\prime}, 1-\xi^{\prime} n_{0}\right)}{u_{1}\left(c, 1-\xi n_{0}\right)}\left[d\left(k^{\prime}, z^{\prime}\right)+p_{\mathrm{e}}\left(k^{\prime}, z^{\prime}\right)\right] Q\left(z, \mathrm{~d} z^{\prime}\right) .
\end{aligned}
$$

But with the behavior of the consumption and capital stock series differing significantly from the canonical case, we would expect the actual values of these quantities to change as a result.

While retaining our emphasis on the link between macroeconomic and financial variables, we lastly consider a non-Walrasian model formulation.

\subsection{A non-Walrasian model with labor contracting}

For this economy, equilibrium will not be optimal and, as a result, cannot be expressed as the solution to a maximization problem as per (1) or (9). The equilibrium must therefore be constructed from an examination of the problems confronting the various agents in the economy. For this reason, our model description is necessarily more detailed than those of sections 3.1 and 3.2.

\subsubsection{Firms}

We hypothesize an economy with a large number of identical firms. Firms are owned by infinitely-lived dynasties of shareholders and undertake all 
investment and hiring decisions. ${ }^{3}$ All firms produce the unique commodity with the same constant returns-to-scale technology as described by a production function of the form $f\left(K, N_{\mathrm{p}}, N_{\mathrm{s}}\right) z$, where $K$ represents an individual firm's capital stock, $z$ is the economy-wide shock to technology common to all firms, and $N_{\mathrm{p}}$ and $N_{\mathrm{s}}$, respectively, denote firm levels of primary and secondary labor employed. (More on this distinction presently.) Firm owners (stockholders) receive the residual profits from production, i.e., the value of output net of the wage bill and taxes. We write $\pi(K, k, z)$ to represent the thus defined profit function of a firm owner with individual capital $K$, when the state of the economy is summarized by the aggregate level of capital stock $k$ and the technology shock $z$. With this notation, the representative shareholder's consumption and savings decisions are assumed to solve the following problem:

$$
\max _{\left\{\left(C_{t},\left(I_{t}\right)\right)\right\}} \mathrm{E}\left(\sum_{t=0}^{\infty} \beta^{t} v\left(C_{t}\right)\right),
$$

subject to

$$
\begin{aligned}
& C_{t}+I_{t} \leq \pi\left(K_{t}, k_{t}, z_{t}\right), \\
& K_{t+1}=(1-\delta) K_{t}+I_{t}, \\
& K_{0} \text { given. }
\end{aligned}
$$

\subsubsection{Workers in the primary sector}

Labor services are provided by a stationary population of workers where each supplies one unit of labor inelastically in each period of his life (there is no disutility to work). A distinctive feature of our model is the assumption that workers do not have access to financial markets: they do not own shares in firms nor can they either borrow or lend. While this may appear as a somewhat extreme assumption, it is made in the spirit of the following two observations. First, workers' main wealth is in the form of their human capital. Yet human capital cannot collateralize loans in modern economies. Second, a large fraction of the population does not own stocks. Mankiw and Zeldes (1991), in fact, report that for the U.S. economy only one quarter of all families own stocks.

The hypothesis of restricted access effectively prevents an optimal allocation of risks via financial markets: workers in this world consume their period

\footnotetext{
${ }^{3}$ We intend that the infinitely-lived dynasty be a proxy for a family for which each generation internalizes the utility of its heirs. Barro (1984) demonstrates that such an organization will behave collectively like the infinitely-lived agent we postulate.
} 
income. ${ }^{4,5}$ Modern economies, however, have developed substitute mechanisms for smoothing consumption. In this paper, we shall focus on the labor market and related institutions as instruments for doing so. One of our primary objectives will be to demonstrate that this enlarged role of labor institutions and arrangements is not without consequences for the dynamics of the economy.

Two types of relationships between firms and workers are postulated. Workers in the primary sector benefit from a life-long association with the firm. They are permanent members of the organization or 'insiders' and the nature of their contract with the firm is such that in exchange for supplying one unit of labor each period of their working life, workers receive compensation which is considerably less variable than their period marginal utility and, in fact, corresponds to an ex post efficient allocation of income risk between primary sector workers and firm owners.

The compensation received by the primary workers must thus be such that the ratio of their ex post marginal utility of consumption to the firm owners' marginal utility of consumption is a constant, $\theta$, across all states of nature and across time. A value for the parameter $\theta$ was chosen so that the expected utility of firm owners under this risk sharing arrangement exceeded their expected utility under a pure Walrasian set-up. This allows us to assert that both firms and workers would voluntarily enter into such arrangements.

Summing up this discussion, the life-time contract between primary sector workers and firm owners implies that each firm will employ its share of the primary sector workforce at a compensation level $w_{\mathrm{p}}(K, k, z)$ implicitly given by

$$
u_{1}\left[w_{\mathrm{p}}(K, k, z)\right]=\theta v_{1}[C(K, k, z)]
$$

where $C(K, k, z)$ solves problem (14) and $u()$ denotes the period utility of (both types of) workers. ${ }^{6}$

Using the language of the contracting literature we assume, in effect, that the firm is contractually bound in perpetuity to the primary workers with the

\footnotetext{
${ }^{4}$ As a consequence of the no borrowing or lending assumption, the worker's optimal consumption problem is a static one. We thus do not need to be specific about their life duration. For simplicity, we assume they live forever as well.

${ }^{5}$ The fact that workers consume their incomes allows us to introduce agent heterogeneity in a convenient way without the challenge of having to keep track of wealth distributions: only one agent effectively accumulates wealth. This heterogeneity is nonetheless nontrivial and the choice of preference parameters for the workers has a substantial impact on the properties of equilibrium.

${ }^{6}$ We may interpret eq. (15) as suggesting that permanent workers are viewed by the firm owner as 'part of the family', in such a way that their utility is included directly in the firm owner objective function: in effect, the period utility function of the firm owner is given by $v(c)+$ $\phi u\left(w_{\mathrm{p}}\right)$. It is clear that eq. (15) will be also satisfied for all $(k, z)$ under this scenario.
} 
form of the (time-invariant) contract defined by the risk sharing rule implicit in eq. (15). Primary workers' consumption volatility is reduced within the period and intertemporally. The latter smoothing comes about from the fact that shareholders are able to smooth their consumption intertemporally and that the relationship defined by eq. (15) de facto imparts some of this smoothing to the primary workers. In effect, the contract serves to substitute for a securities market in which primary workers and shareholders trade risks. $^{7}$

\subsubsection{Secondary sector workers}

At the other extreme, workers in the secondary or 'casual' sector do not have tenure with a firm, but rather only a short-term relationship which may be renewed or not depending on the realization of the firm's productivity shock.

In this paper, we assume that workers of both types are of equal measure which we normalize to be one. Firms take the wage level of secondary workers as given. Their hiring is determined by the standard condition that marginal productivity should cover the real wage. Anticipating the fact that an equilibrium can be characterized as if there were only one firm (employing the economy-wide stock of capital and all employed workers), the level of employment of secondary sector workers, $n_{\mathrm{s}}(k, z)$, will be given by

$$
w_{\mathrm{s}}(k, z)=f_{3}\left[k, 1, n_{\mathrm{s}}(k, z)\right] z,
$$

where $w_{\mathrm{s}}(k, z)$ is the wage level of secondary workers.

Given imperfect capital markets, Walrasian wage determination in the secondary labor market [i.e., $w^{*}(k, z)=f_{3}(k, 1,1) z$ ] will entail considerable income variation. All modern economies have adopted a variety of redistributive schemes; e.g., minimum wage laws, welfare payments, unemployment compensation, etc., which we interpret as having the objective of preventing extremes of income variation. Following Drèze (1989), we capture the effect of these institutions by postulating the existence of a system combining a socially determined wage floor with unemployment compensation financed by a lump-sum tax on firms' profits. We intend for this set-up to reflect not only

\footnotetext{
${ }^{7}$ Could an arrangement between firm owners and permanent workers with a sharing parameter $\theta$ changing over time be a Pareto-superior arrangement to the one we have specified? The answer is no and for the following reason: a constant $\theta$ implies effectively that the intertemporal marginal role of substitution of permanent workers and firm owners will be the same, and this condition is necessary to a Pareto-optimal allocation. With $\theta$ 's changing through time, the marginal rates of substitution will differ implying further gains to intertemporal exchanges between the two types of agents.
} 
what prevails in that segment of the labor market directly affected by minimum wage restrictions but also what prevails in all those professions where union activity significantly affects the compensation level of workers (thereby preventing, in certain circumstances, a full equilibration of the corresponding market).

We shall assume that the wage floor $w_{\mathrm{f}}(k, z)$ and the transfer payments $t(k, z)$ to the unemployed (if any) are determined, on a state-contingent basis, as the solution to the maximization of a weighted sum of agents' period utilities. For every $(k, z), w_{\mathrm{f}}(k, z)$ and $t(k, z)$ solve

$$
\begin{aligned}
& \max _{\left(w_{\mathrm{f}}, t\right\}} \lambda v(c(k, k, z))+u\left(w_{\mathrm{p}}(k, z)\right)+n_{\mathrm{s}}(k, z) u\left(w_{\mathrm{f}}\right) \\
& +\left(1-n_{\mathrm{s}}(k, z)\right) u(t)
\end{aligned}
$$

subject to

$$
w_{\mathrm{f}} \geq t, \quad 1 \geq n_{\mathrm{s}}(k, z) .
$$

In problem (17) above, $n_{\mathrm{s}}(k, z)$ is determined by eq. (16) while $w_{\mathrm{p}}(k, z)$ satisfies eq. (15). The parameter $\lambda$ is the firm owner's weight factor in the government objective function. It will be calibrated so as to insure that capital income's share in the model economy approximates its real-world counterpart. The wage paid to the secondary workers is thus given by

$$
w_{\mathrm{s}}(k, z)=\max \left\{w_{\mathrm{f}}(k, z), w^{*}(k, z)\right\},
$$

where $w^{*}(k, z)$ is the Walrasian determined wage. Problem (17) is appealing because on a period-by-period basis it produces an allocation of resources (with unemployment) which is socially preferred to the Walrasian solution of the secondary labor market. Of course, (17) presupposes - some would argue, with a fair amount of descriptive realism - that the government acts myopically by not taking account of the effect of its wage floor policy on the investment function of the firm owners. Note that some form of myopia has to be assumed on the part of government or society if a nonoptimal level of employment is to be rationalized in the context of this model.

\subsubsection{Equilibrium}

Our set-up can now be summarized as follows. Firm owners determine their investment policy $I()$ by solving problem (14) taking as a given the state-contingent wage of the secondary workers, $w_{\mathrm{s}}(k, z)$, and the state-contingent (lump-sum) tax function, $T(K, k, z)=K / k \cdot t(k, z) \cdot\left(1-n_{s}(k, z)\right.$ ). 
They are also committed through an indefinite contract to employing their share $(K / k)$ of permanent workers with a compensation scheme given by $w_{\mathrm{p}}(K, k, z)$.

These constraints are subsumed in the definition of a representative firm-owner's profit,

$$
\begin{gathered}
\pi(K, k, z)=\max _{N_{\mathrm{s}}}\left\{f\left(K, N_{\mathrm{p}}, N_{\mathrm{s}}\right) z-w_{\mathrm{p}}(k, z) N_{\mathrm{p}}\right. \\
\left.-N_{\mathrm{s}} w_{\mathrm{s}}(k, z)-T(K, k, z)\right\}
\end{gathered}
$$

Note that optimal risk sharing between workers and shareholders may force the residual profit to differ from the return on capital even in the presence of constant returns. Thus we view shareholders as entrepreneurs who contribute whatever capital they have to the production process every period and who receive in return the residual profit after wages and taxes have been paid.

Taking the investment policy as a given - thus ignoring the impact of its policies on the investment rule - the government imposes a wage floor $w_{f}(\cdot)$ and a tax (and transfer) policy $t(k, z)$. In effect we assume that society precommits itself to a social contract - summarized by problem (17) - which is invariant across all future time periods and which benefits secondary workers. As in the case of primary workers, the (social) contract is not renegotiated on a period-by-period basis and in that sense may be viewed as an element of the constitution of the society. This assumes a precommitment technology which differentiates our formulation from that of, e.g., Kydland and Prescott (1977) and Chari et al. (1989).

In equilibrium, individual and aggregate quantities coincide: $K=k, N_{\mathrm{p}}=$ $n_{\mathrm{p}}, T(k, k, z)=t(k, z) \cdot\left(1-n_{\mathrm{s}}(k, z)\right)$, and $N_{\mathrm{s}}=n_{\mathrm{s}}$. Writing in a natural fashion $I(k, k, z) \equiv i(k, z), C(k, k, z) \equiv c(k, z)$, and $w_{\mathrm{p}}(k, k, z) \equiv w_{\mathrm{p}}(k, z)$, we are now in a position to state our definition of equilibrium.

Definition. An equilibrium in this model is an investment policy $i(\cdot)$ and a government policy $\left[w_{\mathrm{f}}(\cdot), t(\cdot)\right]$ such that, given $i(\cdot),\left[w_{\mathrm{f}}(\cdot), t(\cdot)\right]$ solves (17) for all $(k, z)$, while given $\left[w_{\mathrm{f}}(\cdot), t(\cdot)\right], i(\cdot)$ is the solution to (14) with profit defined in (19).

Existence of equilibrium can, in general, be guaranteed provided the technology and preferences satisfy certain substantially restrictive assumptions, which are detailed in Danthine and Donaldson (1991b). A brief overview of the technique (and its computational analogue) is as follows. 
The necessary first-order condition for problem (14) is given by

$$
\begin{aligned}
v_{1}(c)= & v_{1}(\pi(k, z)-i(k, z)) \\
= & \beta \int v_{1}\left(\pi\left(k^{\prime}, z^{\prime}\right)-i\left(k^{\prime}, z^{\prime}\right)\right) \\
& \times f_{1}\left(k^{\prime}, 1, n_{\mathrm{s}}\left(k^{\prime}, z^{\prime}\right)\right) z^{\prime}+(1-\delta) Q\left(z, \mathrm{~d} z^{\prime}\right) .
\end{aligned}
$$

Let $\mathscr{C}$ denote the set of bounded continuous functions defined on $R^{+} \times R^{+}$, and for $i(k, z) \in \mathscr{b}$, define the operator $\mathscr{W}(): \mathscr{b} \rightarrow \mathscr{b} \times \mathscr{b} \times \mathscr{b}$ by

$$
\mathscr{W}(i(k, z))=\left(w_{\mathrm{p}}(k, z), w_{\mathrm{s}}(k, z), t(k, z)\right),
$$

where this latter triple of functions solves (17) together with (16) and (18), given $i(k, z)$. We next define a second operator $\mathscr{I}: b \times b \times b \rightarrow b$ by

$$
\mathscr{I}\left(w_{\mathrm{p}}(k, z), w_{\mathrm{s}}(k, z), t(k, z)\right)=i(k, z),
$$

where $i(k, z)$ solves eq. (20) given ( $\left.w_{\mathrm{p}}(k, z), w_{\mathrm{s}}(k, z), t(k, z)\right)$. Equilibrium for this economy can then be expressed as a function $\hat{i}(k, z) \in \mathscr{C}$ for which

$$
\hat{i}(k, z)=\mathscr{T}(\hat{i}(k, z)) \equiv \mathscr{I}(\mathscr{W}(\hat{i}(k, z))),
$$

i.e., $\hat{i}(k, z)$ is a fixed point of the operator $\mathscr{T}()$.

A simple iterative scheme, which generated a sequence $\left\{i_{n}(k, z)\right\}, i(k, z)=$ $\mathscr{T}\left(i_{n-1}(k, z)\right)$, allowed us to compute the equilibrium $\hat{i}(k, z)$ as the limit of a monotone sequence of functions.

Since workers are prohibited from financial market participation, the expression for the price of a one-period risk-free discount bond (and thus the risk-free rate) as well as the return on the market portfolio are defined only with respect to shareholder preferences and savings behavior. Accordingly, the state conditional price of a one-period risk-free discount bond is given by

$$
p_{\mathrm{b}}(k, z)=\beta \int \frac{v_{1}\left(c\left(k^{\prime}, z^{\prime}\right)\right)}{v_{1}(c(k, z))} Q\left(z, \mathrm{~d} z^{\prime}\right) .
$$

In a like fashion, the (conditional) price $p_{\mathrm{e}}(k, z)$ of the equity security is defined recursively by the equation

$$
p_{\mathrm{e}}(k, z)=\beta \int \frac{v_{1}\left(c\left(k^{\prime}, z^{\prime}\right)\right)}{v_{1}(c(k, z))}\left[d\left(k^{\prime}, z^{\prime}\right)+p_{\mathrm{e}}\left(k^{\prime}, z^{\prime}\right)\right] Q\left(z, \mathrm{~d} z^{\prime}\right),
$$


where $d(k, z)$, the dividend, is defined by

$$
d(k, z)=f\left(k, 1, n_{\mathrm{s}}(k, z)\right) z-w_{\mathrm{p}}(k, z)-w_{\mathrm{s}}(k, z)-i(k, z)
$$

As our notation clearly indicates the expressions for the pricing relationships and thus the rate of return representations are conditional on the state of the economy $(k, z)$. This is true, not only for the non-Walrasian economy but also for the Walrasian economies considered earlier [cf. eqs. (12) and (13)]. For all of these expressions the unconditional mean risk-free rate and return to the market portfolio are defined by, respectively,

$$
\begin{aligned}
& E r_{\mathrm{b}}=\iint r_{\mathrm{b}}(k, z) G(\mathrm{~d} k, \mathrm{~d} z), \\
& \mathrm{E} r_{\mathrm{e}}=\iint r_{\mathrm{e}}(k, z) G(\mathrm{~d} k, \mathrm{~d} z),
\end{aligned}
$$

where $G(\mathrm{~d} k, \mathrm{~d} z)$ denotes the joint stationary distribution on aggregate capital and the shock to technology. Note that $G(\mathrm{~d} k, \mathrm{~d} z)$ will differ substantially for our three model formulations.

\subsection{Anatomy of the risk premium}

Let $m\left(k^{\prime}, z^{\prime} \mid k, z\right)=u_{1}\left(c\left(k^{\prime}, z^{\prime}\right)\right) / u_{1}(c(k, z))\left[\right.$ or $v_{1}\left(c\left(k^{\prime}, z^{\prime}\right)\right) / v_{1}(c(k, z))$, as the case may be]. Then eqs. (4) and (6) (Walrasian model), or (12) and (13) (indivisible labor model), or (24) and (25) (non-Walrasian model) can, respectively, be written as ${ }^{8}$

$$
\begin{aligned}
& 1=\beta R_{\mathrm{b}}(k, z) \int m\left(k^{\prime}, z^{\prime} \mid k, z\right) Q\left(z, \mathrm{~d} z^{\prime}\right), \\
& 1=\beta \int m\left(k^{\prime}, z^{\prime} \mid k, z\right) R_{\mathrm{e}}\left(k^{\prime}, z^{\prime} \mid k, z\right) Q\left(z, \mathrm{~d} z^{\prime}\right),
\end{aligned}
$$

where

$$
R_{\mathrm{b}}(k, z)=1+r_{\mathrm{b}}(k, z)
$$

and

$$
R_{\mathrm{e}}\left(k^{\prime}, z^{\prime} \mid k, z\right)=\frac{p_{\mathrm{e}}\left(k^{\prime}, z^{\prime}\right)+d\left(k^{\prime}, z^{\prime}\right)}{p_{\mathrm{e}}\left(k^{\prime}, z^{\prime}\right)}
$$

\footnotetext{
${ }^{8}$ This section builds on Donaldson and Mehra (1984).
} 
From (30), we obtain

$$
\begin{aligned}
1= & \beta \int m\left(k^{\prime}, z^{\prime} \mid k, z\right) Q\left(z, \mathrm{~d} z^{\prime}\right) \cdot \int R_{\mathrm{e}}\left(k^{\prime}, z^{\prime} \mid k, z\right) Q\left(z, \mathrm{~d} z^{\prime}\right) \\
& +\beta \operatorname{cov}\left[m\left(k^{\prime}, z^{\prime} \mid k, z\right), R_{\mathrm{e}}\left(k^{\prime}, z^{\prime} \mid k, z\right)\right] .
\end{aligned}
$$

Substituting $1 / R_{\mathrm{b}}(k, z)$ for the first term in eq. (31) and rearranging gives the following expression for the conditional premium risk $R_{\mathrm{p}}(k, z)$ :

$$
\begin{aligned}
R_{\mathrm{p}}(k, z) & =\int R_{\mathrm{e}}\left(k^{\prime}, z^{\prime} \mid k, z\right) Q\left(z, \mathrm{~d} z^{\prime}\right)-R_{\mathrm{b}}(k, z) \\
& =-\beta R_{\mathrm{b}}(k, z) \operatorname{cov}\left(\frac{u_{1}\left(c\left(k^{\prime}, z^{\prime}\right)\right)}{u_{1}(c(k, z))}, r_{\mathrm{e}}\left(k^{\prime}, z^{\prime} \mid k, z\right)\right)
\end{aligned}
$$

In accordance with our later hypotheses, let us assume that $u(c, l)$ is of the form $u(c, l)=\tilde{u}(c)+g(l)$. Approximate $\tilde{u}(c)$ by its second-order Taylor series expansion; i.e., $\tilde{u}(c)=a c-(b / 2) c^{2}$ for constants $a>0, b>0$. Noting that the coefficient of relative risk aversion, $\psi$, is given by $(b c / a-b c)$, eq. (34) can then be written as

$$
\begin{aligned}
R_{\mathrm{p}}(k, z)= & -\beta R_{\mathrm{b}}(k, z) \operatorname{cov}\left(\frac{a-b c\left(k^{\prime}, z^{\prime}\right)}{a-b c(k, z)}, r_{\mathrm{e}}\left(k^{\prime}, z^{\prime} \mid k, z\right)\right) \\
= & -\beta R_{\mathrm{b}}(k, z)\left(\frac{-b}{a-b c(k, z)}\right) \\
& \times \operatorname{cov}\left(c\left(k^{\prime}, z^{\prime}\right), r_{\mathrm{e}}\left(k^{\prime}, z^{\prime} \mid k, z\right)\right) \\
= & \beta R_{\mathrm{b}}(k, z)\left(\frac{b c(k, z)}{a-b c(k, z)}\right) \\
& \times \operatorname{cov}\left(\frac{c\left(k^{\prime}, z^{\prime}\right)}{c(k, z)}, r_{\mathrm{e}}\left(k^{\prime}, z^{\prime} \mid k, z\right)\right), \\
R_{\mathrm{p}}(k, z)= & \beta \psi R_{\mathrm{b}}(k, z) \rho\left(\frac{c\left(k^{\prime}, z^{\prime}\right)}{c(k, z)}, r_{\mathrm{e}}\left(k^{\prime}, z^{\prime} \mid k, z\right)\right) \\
& \cdot \sigma\left(c\left(k^{\prime}, z^{\prime}\right) / c(k, z)\right) \sigma\left(r_{\mathrm{e}}\left(k^{\prime}, z^{\prime} \mid k, z\right)\right),
\end{aligned}
$$


where the latter terms represent the standard deviations of the indicated series. It follows that the unconditional risk premium, $R_{\mathrm{p}}$, is given by (to a good approximation)

$$
\begin{aligned}
R_{\mathrm{p}}= & \iint \beta \psi R_{\mathrm{b}}(k, z) \rho\left(\frac{c\left(k^{\prime}, z^{\prime}\right)}{c(k, z)}, r_{\mathrm{e}}\left(k^{\prime}, z^{\prime} \mid k, z\right)\right) \\
& \cdot \sigma\left(c\left(k^{\prime}, z^{\prime}\right) / c(k, z)\right) \sigma\left(r_{\mathrm{e}}\left(k^{\prime}, z^{\prime} \mid k, z\right)\right) G(\mathrm{~d} k, \mathrm{~d} z) .
\end{aligned}
$$

This expression makes clear the principal (endogenous) determinants of the risk premium: the standard deviation of the consumption growth rate, the standard deviation of the return on the equity security, and the correlation of the consumption growth rate with the market relurn. Our analysis of the financial performance of our three model paradigms thus naturally focuses on these three quantities.

\section{Model performance}

For the canonical and indivisible labor supply models, Gary Hansen provided us with the equilibrium decision rules. These rules were used to construct a time series of the relevant macrovariables - consumption, investment, etc., and it is with respect to these stationary time series that the financial and macro statistics were computed. In the case of the non-Walrasian model, we followed the procedure noted earlier to obtain the equilibrium $i(k, z)$. Given the equilibrium investment function $i(k, z)$, all the various time series were easily generated.

With regard to the choice of functional forms, the period utility function for the canonical and indivisible labor economies, following Hansen (1985), was chosen to be $u(c, l)=\log c+B \log l, B=\frac{2}{3}$; for the non-Walrasian model $v(c)=\log c$ (profit earner utility). For the latter model it was also assumed that workers are more risk-averse than entrepreneurs. To accommodate this assumption, the period utility function common to both old and young workers was chosen to be $c^{1-\psi} / 1-\psi$, with $\psi=7$, in line with earlier microstudies, notably Drèze (1981).

As for production technologies, $f(k, n)=k^{\alpha} n^{1-\alpha}$, with $\alpha=0.36$, for the canonical and indivisible labor models. A natural adaptation of this general form was chosen for the non-Walrasian economy: $f\left(k, n_{\mathrm{p}}, n_{\mathrm{s}}\right)=$ $M k^{\alpha} n_{\mathrm{p}}^{\nu(1}{ }^{\alpha)} n_{\mathrm{s}}^{(1-\nu)(1-\alpha)}$, with $v=\frac{1}{2}$ and $\alpha=0.36$. The parameter $M$ is purely a scale parameter; it was chosen to fix the level of unemployment at 5 percent which appears reasonable for the U.S. economy. As noted earlier the parameter $\theta$ was determined entirely endogenously within the model such as to give the expected utility of profit earners with and without risk sharing 
labor contracts to the old as being the same. Lastly, the parameter $\lambda$ determines the distribution of income between profit earners and workers.

For all the models, $\beta$ was fixed at 0.99 (which implicitly defines the model period as corresponding to a quarter). As to the assumed shock process, $z^{\prime}=\phi z+\varepsilon_{t}^{\prime}$, with $\phi=0.95$ and $\varepsilon_{t}^{\prime} \sim$ Normal $(\mu=0.05, \sigma=0.00712)$ for the canonical and indivisible labor models. In the non-Walrasian formulation, $z$ was required to follow a two-state shock process with transition probabilities given by

$$
\begin{array}{cc}
z_{1} & z_{2} \\
z_{1} & \left(\begin{array}{cc}
\eta & 1-\eta \\
1-\eta & \eta
\end{array}\right) .
\end{array}
$$

The parameters $z_{1}, z_{2}$, and $\eta$ were given the values of $1.025,0.975$, and 0.975 , respectively. Under this assignment the persistence and mean of the two-state process coincide with that of the autoregressive process above, while the standard deviation is approximately half as great. Relative to the Walrasian models, the non-Walrasian formulation consistently requires a lower shock variation to achieve the same standard deviation of output.

We are now positioned to review the results of our numerical study.

\subsection{Macrovariables: Comparative analysis}

In table 3 we summarize the performance of the three models with regard to the basic macroeconomic aggregates.

As in U.S. data, investment is more variable than output, which is in turn more variable than total consumption for all three models. The presence of

Table 3

\begin{tabular}{|c|c|c|c|c|c|c|}
\hline & \multicolumn{2}{|c|}{$\begin{array}{c}\text { Canonical } \\
\text { model }\end{array}$} & \multicolumn{2}{|c|}{$\begin{array}{l}\text { Indivisible } \\
\text { labor model }\end{array}$} & \multicolumn{2}{|c|}{$\begin{array}{c}\text { Non-Walrasian } \\
\text { model }\end{array}$} \\
\hline & (a) & (b) & (a) & (b) & (a) & (b) \\
\hline Output & 1.35 & 1.00 & 1.76 & 1.00 & 1.76 & 1.00 \\
\hline Total consumption & 0.42 & 0.89 & 0.51 & 0.87 & 0.34 & 0.69 \\
\hline (i) Shareholder consumption & & & & & 5.36 & 0.98 \\
\hline (ii) Total worker consumption & & & & & 0.22 & 0.10 \\
\hline Investment & 4.24 & 0.99 & 5.71 & 0.99 & 6.08 & 0.99 \\
\hline Capital stock & 0.36 & 0.06 & 0.47 & 0.05 & 0.54 & 0.03 \\
\hline Total hours & 0.70 & 0.98 & 1.35 & 0.98 & 1.26 & 0.98 \\
\hline Average productivity & 0.68 & 0.98 & 0.50 & 0.87 & 0.61 & 0.91 \\
\hline Unemployment rate & & & & & & \\
\hline
\end{tabular}

Standard deviation in percent (a), correlation with output (b). ${ }^{\mathrm{a}}$

\footnotetext{
${ }^{\mathrm{a}}$ The model statistics were computed from detrended data using the procedure of Hodrick and Prescott (1980).
} 
non-Walrasian features is clearly not inconsistent with the most basic characteristics of the business cycle. Nevertheless, in this as in the other two models, there is evidence of excessive consumption smoothing. With regard to the relative variability of hours vis-a-vis average productivity, both the invisible labor and non-Walrasian models perform much better than the canonical model. Indeed, the employment-productivity variability paradox can be viewed as solved in both these formulations.

Shareholder consumption in the non-Walrasian model is seen to vary proportionately much more than worker consumption. This is to be expected in light of the fact that workers are substantially more risk-averse than shareholders and that, as a consequence, substantial income variation will be transferred from workers of both vintages to shareholders in regions of unemployment. Mankiw and Zeldes (1991) provide evidence for this assertion by examining the ratio of the standard deviation of consumption growth for shareholders to that of nonshareholders, and find it to be about 1.5 for the data they examine. In our model economy, the same ratio assumes a value of 1.6 (unfiltered data). This statistic has no counterpart in the other model formulations.

\subsection{Financial quantities: New puzzles}

Table 4 provides a statistical summary of the performance of the three models along the relevant financial dimensions.

The first columns of table 4 record the results obtained for the Walrasian model. The equity premium is extremely small, 0.03 percent: the annualized risk-free rate is not different from the average return on the market at 4.1

Table 4

Summary financial statistics, annualized, in percent; unconditional mean values (a), unconditional standard deviation (b).

\begin{tabular}{|c|c|c|c|c|c|c|}
\hline & \multicolumn{2}{|c|}{$\begin{array}{l}\text { Walrasian } \\
\text { economy }\end{array}$} & \multicolumn{2}{|c|}{$\begin{array}{c}\text { Indivisible labor } \\
\text { economy }\end{array}$} & \multicolumn{2}{|c|}{$\begin{array}{c}\text { Non-Walrasian } \\
\text { economy }\end{array}$} \\
\hline & (a) & (b) & (a) & (b) & (a) & (b) \\
\hline$r_{\mathrm{e}}$ & 4.1 & 0.4 & 4.15 & 0.48 & 4.56 & 0.84 \\
\hline$r_{b}$ & 4.1 & 0.2 & 4.11 & 0.20 & 3.98 & 0.80 \\
\hline$r_{p}$ & 0.03 & 0.3 & 0.04 & 0.44 & 0.58 & 0.06 \\
\hline $\mathrm{E}\left(c_{t+1} / c_{t}\right)$ & \multicolumn{2}{|c|}{0.0000} & \multicolumn{2}{|c|}{$0.0001^{\mathrm{a}}$} & \multicolumn{2}{|c|}{$0.0007^{\mathrm{a}}$} \\
\hline$v\left(c_{t+1} / c_{t}\right)$ & \multicolumn{2}{|c|}{$0.66 \%$} & \multicolumn{2}{|c|}{$0.71 \%$} & \multicolumn{2}{|c|}{$4.3 \%$} \\
\hline$\rho\left(r_{\mathrm{e}}, c_{t+1} / c_{t}\right)^{\mathrm{b}}$ & \multicolumn{2}{|c|}{0.81} & \multicolumn{2}{|c|}{0.67} & \multicolumn{2}{|c|}{0.06} \\
\hline$\rho\left(r_{\mathrm{e}}, M R S\right)^{\mathrm{b}}$ & \multicolumn{2}{|c|}{-0.15} & \multicolumn{2}{|c|}{-0.15} & \multicolumn{2}{|c|}{-0.05} \\
\hline$\rho\left(r_{\mathrm{b}}, M R S\right)^{\mathrm{b}}$ & \multicolumn{2}{|c|}{-0.18} & \multicolumn{2}{|c|}{-0.20} & \multicolumn{2}{|c|}{-0.05} \\
\hline
\end{tabular}

\footnotetext{
a Theoretically zero for a stationary economy.

${ }^{b}$ Quarterly correlations.
} 
percent. This means that the return on the market is too low while the risk-free return is too high. The small equity premium is due partly to the excessive consumption smoothing alluded to earlier: the variability of consumption growth is significantly lower than what is observed in reality. Another more striking source of the model's failure is its inability to replicate the large variability observed for the market return - the standard deviation of $r_{\mathrm{e}}$ is 0.8 percent in the artificial economy as opposed to 16.5 percent in reality.

The third and fourth columns of table 4 demonstrate that the indivisible labor model does not represent a significant improvement over the Walrasian paradigm. The equity premium remains essentially zero (4 hundredths of 1 percent) and for basically the same reason: consumption growth variation is too small and the market return does not vary nearly enough (1 percent as against 16.5 percent for rcal world data). Note that in both models considered so far the variability of the risk-free rate is too small as well: approximately 4 tenths of 1 percent vis-a-vis 5.7 percent in reality.

The results obtained for the non-Walrasian model are closer to real-world observations along all dimensions but one. The market return is larger, the risk-free rate lower, and the equity premium increases to 0.6 percent. While this is ten times too small, it is nevertheless considerably better than the previous two models. It is also higher ( 0.2 percent) than the maximum value obtained by Mehra and Prescott (1985). The improvement in the results is mainly due to the increase in the standard deviation of the growth rate in consumption. This is made possible by the fact that the relevant consumption aggregate for the non-Walrasian model formulation is not aggregate consumption, but rather the consumption of stockholders alone. The standard deviation of the return on the equity security is also higher than in the other two models. Nevertheless, it remains about twenty times too small. On the other hand - and somewhat surprisingly - the correlation of the return on the market with the growth rate in consumption falls.

It thus appears that the equity premium puzzle remains fundamentally robust to this class of models. It could not be otherwise for the Walrasian and indivisible labor models, as they fall entirely within the framework of Mehra and Prescott (1985). Our analysis serves principally to suggest additional sources of model falsification. In the non-Walrasian formulation, however, a new modeling element was introduced in the form of the distinction implied between stockholders' and nonstockholders' consumption. But despite the clear improvement this distinction makes possible vis-a-vis the standard deviation of consumption growth, the failure of the model along the other dimensions prevents a full resolution of the equity premium puzzle.

In particular, the observed volatility of the market return constitutes as much of a puzzle from the standpoint of these theories. Without major alterations to the assumed production technology, we doubt that RBC 
models will be able to replicate the observation that the market return is substantially more volatile than the aggregate product.

The basis of this assertion is most clearly seen in the case of a canonical model. Under the customary Cobb-Douglas technology specification (with $\left.y \equiv f(k, n) z=k^{\alpha} n^{1-\alpha} z\right)$

$$
f_{1}(k, n) z=\alpha y / k
$$

With the gross return on the equity security given by

$$
\begin{aligned}
R_{\mathrm{e}}\left(k^{\prime}, z^{\prime} \mid k, z\right) & =\beta\left[f_{1}\left(k^{\prime}, n^{\prime}\right) z^{\prime}+(1-\delta)\right] \\
& =\alpha \beta y^{\prime} / k^{\prime}+\beta(1-\delta),
\end{aligned}
$$

we can assert that in the stationary state

$$
\operatorname{var}\left(R_{\mathrm{e}}\right)=\operatorname{var}\left(r_{\mathrm{e}}\right)=\alpha^{2} \beta^{2} \operatorname{var}(y / k),
$$

where these are to be interpreted as unconditional variances. For the equality to be satisfied, with $\alpha=0.36$ and $\beta=0.99$, the $\operatorname{var}(y / k)$ must be nearly eight times larger than $\operatorname{var}\left(r_{\mathrm{e}}\right)$, which is not observed. Sufficient return volatility will be possible only if either the fundamental underlying technology or the relationship of equity returns to the marginal productivity of capital changes significantly.

Furthermore, all three RBC models considered here predict a risk-free rate much smoother and significantly higher than what is inferred from real-world observations. In light of the results of the RBC models we have examined the equity premium and risk-free rate puzzles are intimately related: if the equity premium is too small, it is not so much the result of an insufficient market return but rather the result of a risk-free rate that is too large. This assertion is reinforced by the fact that all the models considered in this paper are stationary, a property which leads to understating of the risk-free rate. In a growing economy, future consumption will typically exceed current consumption. Since the marginal utility of future consumption is less than present consumption, real interest rates will be higher on average.

To conclude, it is of interest to pose the following question: suppose an outside observer were to mistake our heterogeneous agent economy for one in which all decisions are undertaken by a representative agent. What level of risk aversion would he infer as necessary to generate the risk premium of our model given the behavior of its aggregate consumption series? We can efficiently provide an answer to this question by using the following formula 
Table 5

Estimating $\psi{ }^{\mathrm{a}}$

\begin{tabular}{lrr}
\hline Data series employed & $\psi=1$ & $\psi=3$ \\
\hline Profit earner consumption & 0.41 & 1.54 \\
Total consumption & 10.13 & 17.02 \\
\hline
\end{tabular}

${ }^{a}$ Other parameters as in table 4.

of Mankiw and Zeldes (1991) or Grossman and Shiller (1982):

$$
\begin{aligned}
\mathrm{E}\left(r_{\mathrm{e}}(k, z)-r_{\mathrm{b}}(k, z)\right)= & \psi \rho\left(r_{\mathrm{e}}(k, z)-r_{\mathrm{b}}(k, z), \Delta \hat{c}(k, z)\right) \\
& \cdot \sigma(\Delta \hat{c}(k, z)) \\
& \cdot \sigma\left(r_{\mathrm{e}}(k, z)-r_{\mathrm{b}}(k, z)\right)
\end{aligned}
$$

where $\sigma$ denotes the standard deviation of the indicated time series and $\Delta \hat{c}(k, z)$ is defined by

$$
\frac{\hat{c}\left(k^{\prime}, z^{\prime}\right)}{\hat{c}(k, z)}-1
$$

with $\hat{c}(k, z)$ measuring either shareholder consumption or total consumption.

Since this formula applies strictly to a world of continuous transactions, it is necessary to check that the bias introduced by a discrete time setting is not too serious by first recovering the CRRA of stockholders from their own consumption series. As shown in the first line of table 5, where we also computed the analogous quantity for the case of shareholder $\psi=3$, for our model economy eq. (39) leads to understating the risk aversion parameter: $\hat{\psi}$ (estimate) $=0.41$ instead of 1 in the $\log (c)$ case, 1.54 instead of 3 in the other one. This gives us confidence that our estimates of the risk aversion parameter of the representative agent can be viewed as lower bounds for the actual parameter values.

Now the answer to our original questions is to be found on the second line of table 5, and it is striking. For the case where the utility of the stockholders is logarithmic, $\psi=1$, the mistaken outside observer would conclude that the representative agent possessed a $C R R A$ exceeding 10 . For the case of $\psi=3$, the aggregate consumption data would lead him to conclude that the economy was operating according to the wishes of a very risk-averse representative agent with a $C R R A$ of 17 (the risk premium in this case is approximately 0.7 percent). 
We feel this result best illustrates the power of the capital and labor market frictions we have introduced to alter the riskiness of the environment facing investors. In this case, furthermore, the (erroneous) use of aggregate consumption data leads to inferring a societal CRRA which substantially exceeds the $C R R A$ of either of the economy's constitutent group. This result suggests that caution should be exercised in drawing conclusions about the fundamental validity of the CCAPM from implausible estimates of the CRRA obtained under representative agent modeling assumptions.

\section{Summary and concluding comments}

We have argued that CCAPM-related financial as well as macroeconomic stylized facts should be used to test RBC models. Such cross-model verification is warranted since the consumption and savings decisions of the same economic agents are at the heart of both paradigms (CCAPM and RBC). This exercise reinforces the claim made elsewhere [Danthine and Donaldson (1991b)] that non-Walrasian types of frictions are not only compatible with, but also improve the power of, RBC models to replicate observed regularities: the results obtained for the risk sharing model are closer to real world observations along all dimensions considered but one.

It remains, however, that the three $\mathrm{RBC}$ models dealt with in this paper are falsificd by financial statistics. To the equity premium and risk-free rate puzzles, we add an excess volatility puzzle: the essential inability of these models to replicate the observation that the market return is fundamentally more volatile than the national product.

Our non-Walrasian model is one with agent heterogeneity. The power of the risk shifting mechanism we have analyzed is made clear in recovering the preferences of the representative agent who would make the risk premium obtained in the model consistent with four aggregate consumption series. We get an estimate for the risk aversion parameter substantially in excess of what is commonly viewed as plausible. The estimate is also substantially higher than the risk aversion parameter of either constitutent group in our economy.

\section{References}

Abel, A., 1990, Asset prices under habit formation and catching up with the Jones, American Economic Review Papers and Proceedings 80, 38-42.

Aiyagari, S.R. and M. Gertler, 1991, Asset returns with transactions costs and uninsured individual risks, Journal of Monetary Economics 27, 311-332.

Barro, R., 1984, Are government bonds net wealth?, Journal of Political Economy 85, 1095-1117.

Breeden, D.T., 1979, An intertemporal capital asset pricing model with stochastic consumption and investment opportunities, Journal of Financial Economics 7, 265-291.

Brock, W.A., 1979, $\Lambda \mathrm{n}$ integration of stochastic growth theory and the thcory of finance, Part $\mathrm{I}$ : The growth model, in: J. Green and J. Scheinkman, eds., General equilibrium, growth, and trade (Academic Press, New York, NY). 
Brock, W.A., 1982, Asset prices in a production economy, in: J.J. McCall, ed., The economics of information and uncertainty (University of Chicago Press, Chicago, IL).

Chari, V.V., P. Kehoe, and E.C. Prescott, 1989, Time consistency and policy, in: R. Barro, ed., Modern business cycle theory (Harvard University Press, Cambridge, MA).

Coleman, W.J., 1991, Equilibrium in an economy with capital and taxes on production, Econometrica 59, 1091-1104.

Constantinides, G.M., 1990, Habit formation: A resolution of the equity premium puzzle, Journal of Political Economy 98, 519-543.

Cox, J., J. Ingersoll, and S.A. Ross, 1985, An intertemporal general equilibrium model of asset prices, Econometrica 53, 363-384.

Danthine, J.P. and J.B. Donaldson, 1990, Efficiency wages and the business cycle puzzle, European Economic Review 34, 1275-1301.

Danthine, J.P. and J.B. Donaldson, 1991a, Risk sharing, the minimum wage, and the business cycle, in: W. Barnett, B. Cornet, C. d'Aspremont, J.J. Gabsewicz, and A. Mas-Colell, eds., Equilibrium theory and applications (Cambridge University Press, Cambridge).

Danthine, J.P. and J.B. Donaldson, 1991b, Methodological and empirical issues in real business cycle theory, European Economic Review, forthcoming.

Danthine, J.P. and J.B. Donaldson, 1991c, Risk sharing in the business cycle, European Economic Review, forthcoming.

Donaldson, J. B. and R. Mehra, 1984, Comparative dynamics of an equilibrium intertemporal asset pricing model, Review of Economic Studies 51, 491-508.

Drèze, J.H., 1981, Inferring risk tolerance from deductibles in insurance contracts, Geneva Papers on Risk and Insurance 20, 48-52.

Drèze, J.H., 1989, Labor management, contracts, and capital markets: A general equilibrium approach (Basil Blackwell, Oxford).

Grossman, S. and R. Schiller, 1982, Consumption correlatedness and risk measurement in economies with non-traded assets and heterogeneous information, Journal of Financial Economics 10, 195-210.

Hansen, G., 1985, Indivisible labor and the business cycle, Journal of Monetary Economics 16 , 309-327.

Hodrick, R.J. and E.C. Prescott, 1980, Post-war U.S. business cycles, GSIA working paper (Carnegie Mellon University, Pittsburgh, PA).

lbbotson, R. and R.A. Sinquefeld, 1979, Stocks, bonds, bills, and inflation: Historical returns (1926-1978) (Financial Analysts' Research Foundations, Charlottesville, VA).

Kydland, F. and E.C. Prescott, 1977, Rules rather than discretion: The inconsistency of optimal plans, Journal of Political Economy 85, 473-491.

Kydland, F. and E.C. Prescott, 1982, Time to build and aggregate fluctuations, Econometrica 50, $1345-1370$.

Lucas, R.E., Jr., 1978, Asset prices in an exchange economy, Econometrica 66, 1429-1445.

Mankiw, N.G., 1986, The equity premium and the concentration of aggregate shocks, Journal of Financial Economics 17, 211-219.

Mankiw, N.B. and S.P. Zeldes, 1991, The consumption of stockholders and non-stockholders, Journal of Financial Economics 29, 97-112.

Mehra, R., 1988, On the existence and representation of equilibrium in an economy with growth and nonstationary consumption, International Economic Review 29, 131-135.

Mehra, R. and E.C. Prescott, 1985, The equity premium: A puzzle, Journal of Monetary Economics 15, 145-161.

Merton, R.C., 1973, An intertemporal asset pricing model, Econometrica 41, 867-887.

Nason, J.N., 1988, The equity premium and time-varying risk behavior, Finance and economics discussion paper no. 11 (Board of Governors of the Federal Reserve, Washington, DC).

Prescott, E.C., 1986, Theory ahead of business cycle measurement, Federal Reserve Bank of Minneapolis Quarterly Review 10, 9-22.

Prescott, E.C. and R. Mehra, 1980, Recursive competitive equilibrium: The case of homogeneous households, Econometrica 48, 1365-1379.

Reitz, T.A., 1988, The equity premium: A solution, Journal of Monetary Economics 22, 117-133. 